\title{
Spark Plasma Sintering of Ceramics: From Modeling to Practice
}

\author{
Michael Stuer ${ }^{1, *} \mathbb{0}$, Paul Bowen ${ }^{2}$ and Zhe Zhao ${ }^{3, *}$ \\ 1 High Performance Ceramics Laboratory, Functional Materials, Swiss Federal Laboratories for Materials \\ Science and Technology (Empa), Überlandstrasse 129, CH-8600 Dübendorf, Switzerland \\ 2 Powder Technology Group, Construction Materials Laboratory, Materials Institute, Swiss Federal Institute of \\ Technology Lausanne, CH-1015 Lausanne, Switzerland; paul.bowen@epfl.ch \\ 3 School of Material Science and Engineering, Shanghai Institute of Technology, 100 Haiquan Rd, Fengxian Qu, \\ Shanghai 201418, China \\ * Correspondence: michael.stuer@empa.ch (M.S.); zhezhao@sit.edu.cn (Z.Z.); Tel.: +41-58-765-4183 (M.S.)
}

Received: 29 October 2020; Accepted: 16 November 2020; Published: 17 November 2020

\begin{abstract}
Summarizing the work of nearly a decade of research on spark plasma sintering (SPS), a review is given on the specificities and key factors to be considered in SPS of ceramic materials, based on the authors' own research. Alumina is used primarily as a model material throughout the review. Intrinsic inhomogeneities linked to SPS and operational parameters, which depend on the generation of atomistic scale defects, are discussed in detail to explain regularly observed inhomogeneities reported in literature. Adopting an engineering approach to overcome these inherent issues, a successful processing path is laid out towards the mastering of SPS in a wide range of research and industrial settings.
\end{abstract}

Keywords: SPS; FEM; ceramics; alumina; sintering; microstructure; PECS; FAST; optical properties

\section{Introduction}

Since its introduction, spark plasma sintering (SPS) has gained significant interest in the ceramic community due to its ability to produce ceramics and ceramic-based composites with short sintering cycles and reduced dwell temperatures [1-8]. A longstanding debate about the origins for the improved densification observed during SPS [9-14] arose, given the reported similar apparent activation energies for sintering in SPS compared to other sintering techniques (depending on the sintering stage) [14-16]. This controversy gave rise to field assisted sintering technique (FAST) and pulsed electric current sintering (PECS) as alternative terms for the more commonly used "SPS". Zhang et al. [12] have shown first evidence for the occurrence of a spark discharge in SPS, which appears to support the hypothesis of improved densification due to adsorbed gas and impurity elimination as a result of the spark discharge event $[9,10,17,18]$.

In addition to the fast densification rates observed in SPS, the pressure and temperature profiles as well as the die geometry effects on the electrical-thermal-mechanical system involved in SPS are of prime relevance [19-21]. Indeed, on the way towards industrial relevance of SPS processes, advanced understanding of such physical and geometrical factors is needed to produce globally homogeneous ceramic parts. Due to the highly dynamic nature of the SPS process, temperature, pressure, and current density gradients may lead to inhomogeneous sintering, which may be highly undesirable. In SPS, highest efforts must thus be made not only to ensure homogeneous powder packing or green body shaping, but also to warrant homogeneous sintering on a part scale. Thus, a broad understanding of the SPS set-up is required at a multi-scale level to fully capture the true phenomenology of the process. 
As a consequence of the improved densification rates and the rapid sintering cycles, SPS has developed into a prime sintering technique to produce transparent ceramic materials [3,5,22-33]. Working with cubic materials, the optical properties are independent of grain size. For non-cubic birefringent materials such as alumina, however, the densification versus grain growth rate is of prime importance. Here, scattering events not only occur from pores and secondary phases, but also from the very randomly oriented grains themselves [32,34-36]. It is thus of utmost interest to achieve pore-free microstructure with minimal grain growth in spite of fine sub-micron starting powders. Careful (and slow) colloidal processing and/or selective doping are thus important prerequisites to be ideally combined with fast sintering cycles and high sintering pressures or two-step sintering approaches [37-40]. In the realm of complexions, the fast heating and densification rates as much as lower sintering temperatures in SPS efficiently help avoiding complexion transitions, which lead to fast-moving grain boundaries and extensive grain growth [41-46].

The purpose of this paper is to show how an increased scientific understanding of SPS has led to improved microstructural control of SPS ceramics. It shows that a deeper understanding of the mechanisms involved in SPS opens new routes for future scientific developments, as well as delivering an efficient knowledge base for practical manufacturing aspects with industrial relevance. Starting from finite element modeling (FEM), the relevance of a multi-physics approach is laid out, ignoring the atomistic diffusion mechanisms involved in SPS. The substantial equivalence between SPS and other sintering techniques is corroborated through an extensive apparent energy of densification analysis, before illustrating that the moment of pressure application, more than the pressure itself, is an important parameter to control the ceramics properties and stability on an atomistic scale. Finally, we lay out the benefits of SPS for future ceramic research, on the way towards advanced grain boundary engineering and microstructural control of ceramic materials, still a largely unresolved challenge in current ceramic research $[43,45,46]$.

\section{Towards Demystifying SPS by FEM Modeling}

The extensive research on transparent ceramic materials triggered by SPS has, at the same time, proven to be a useful tool in assessing SPS itself. Through visual and spectroscopic observations, rapidly accessible information can be provided regarding porosity, grain size, and color center generating defects in the ceramic material [32,47]. Working on transparent magnesium spinel has proven particularly resourceful, because of the large sensitivity of its optical properties on dislocation stabilized oxygen vacancies [47]. The optical properties of $\mathrm{SPS} \mathrm{MgAl}_{2} \mathrm{O}_{4}$ samples strongly evolve with the uniaxial pressure applied during the sintering cycle's heating ramp (Figure 1). This evolution revealing a radial anisotropy suggests locally varying sintering conditions as a potential root cause.

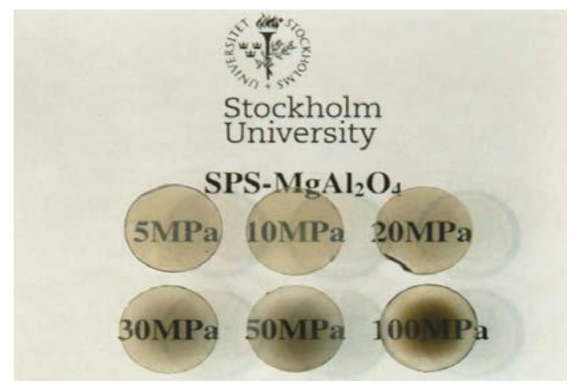

Figure 1. The $12 \mathrm{~mm}$ diameter magnesium spinel samples demonstrating sintering inhomogeneities occurring during spark plasma sintering (SPS). Direct observation of the inhomogeneities is possible due to the observed optical differences, accentuated with increasing uniaxial pressure applied during the heating ramp prior to reaching the final dwell temperature $\left(1300^{\circ} \mathrm{C}\right.$ for $\left.3 \mathrm{~min}\right)$. The brownish-black discoloration is believed to be directly linked to dislocation stabilized oxygen vacancies, likely to be generated as a result of superplastic deformation occurring at low temperature [47]. (reprinted with permission from Elsevier). 
Based on these observations, FEM was performed in order to better understand the underlying mechanisms that could lead to the observed anisotropies. A multi-physics approach was chosen in order to develop a coupled electric-thermal-mechanical model able to explain recurrent inhomogeneities reported in literature as well as in our own research [48]. Herein, alumina was used as a standard material and real densification data were used to improve the accuracy of the model predictions. Furthermore, for the first time, the current was controlled through a numeric proportional-integral-differential (PID) module in COMSOL, required to properly account for non-linear variation of current densities as a result of dynamically changing material properties (Figure 2).

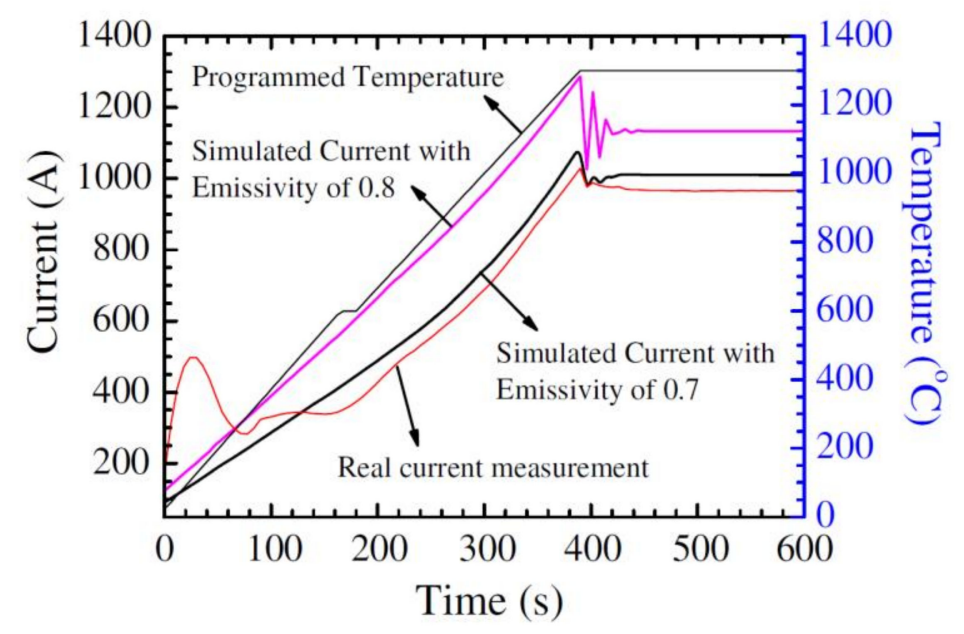

Figure 2. Modeled and measured input currents for a given programmed temperature profile as a function of the emissivity (Stefan-Boltzmann law) used for the graphite die. With an emissivity of 0.7 , reasonable equivalence is given between the experimental and simulated currents. At low temperature, current densities differ more broadly due to the experimental pyrometer limitations at low temperatures [48]. (reprinted with permission from Elsevier).

In addition to the effect of the heating rate, where a good agreement was reached with previous studies $[19,21]$, it could be shown that the effect of the die size has to be considered carefully in absence of any linear correlation. Whilst for small $(\approx 12 \mathrm{~mm})$ and large $(\approx 50 \mathrm{~mm})$ sample diameters, the thermal gradients within the samples are relatively moderate within $\approx 30 \mathrm{~K}$, they pass through a maximum for intermediate sizes, where thermal gradients can reach $>70 \mathrm{~K}$. These results highlight that careful selection of the die and sample size is required for reliable implementation of SPS in a manufacturing setting. In addition, the study highlighted the existence of a critical die/sample diameter above which higher heating rates lead towards smaller thermal gradients, opposite to the observed heating effect at smaller diameters. This suggests that the heating rate may have to be considered, where applicable, as a means to control the sample homogeneity in addition to its role in the microstructure development. These results could be qualitatively verified through radial grain size measurements on samples with sintering cycles interrupted at the moment of reaching the dwell temperature (Figure 3). A more appropriate temperature/stress relationship would be required in the model for more quantitative results $[48,49]$. 


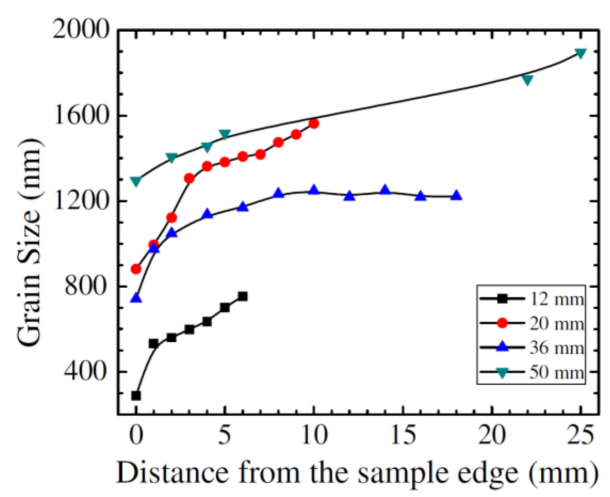

Figure 3. Grain size evolution for pure alumina samples as a function of the distance from the sample edge and the die/sample diameter. For all samples sintered in SPS, a constant $100 \mathrm{~K} / \mathrm{min}$ heating rate was used up to a peak temperature if $1300{ }^{\circ} \mathrm{C}$ with no dwell time. For the $20 \mathrm{~mm}$ diameter sample, an abnormally large grain size difference can be observed in accordance with the predictions from the modeling work [48]. (reprinted with permission from Elsevier).

These temperature gradients are an intrinsic challenge in SPS, especially when aiming for fast heating rates with short sintering cycles. Although an appropriate die and graphite tool design can improve the gradient amplitude, it does not manage to suppress its occurrence [50]. Whilst working with SPS, other strategies seem thus to be more promising taking advantage of the sintering theory and kinetics which stipulates that grain growth mostly occurs in the final sintering step. Consequently, two-step pressure profiles have been successfully explored as a means to efficiently reduce the grain size inhomogeneity through the sample thickness and diameter [51]. As illustrated in Figure 4, the densification delay induced by the 2-step pressure profile decreases the overall grain size after sintering. The entry into the third sintering stage, where grain growth is mostly expected to occur, is delayed in the sintering cycles, noticeably reducing the available time for grain growth to occur and this grain size inhomogeneities to develop. Grain growth inhibition by solute drag as a consequence of appropriate selective doping has a further positive effect on the microstructural homogeneity during SPS [51].

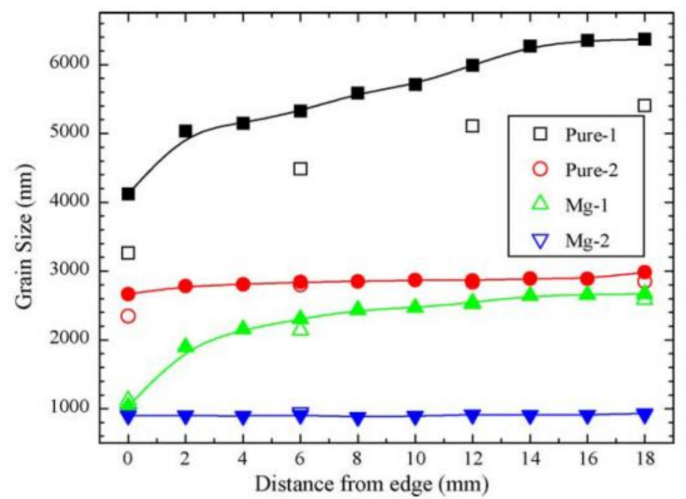

Figure 4. Example of the grain size distribution along radial direction for SPS sintered pure and Mg-doped alumina samples. Filled marks are taken from the sample middle and empty marks from the sample surface with respect to the sample thickness. All samples were sintered at $1350{ }^{\circ} \mathrm{C}$ with a dwell time of $5 \mathrm{~min}$. For the "-1" samples, the uniaxial sintering pressure of $100 \mathrm{MPa}$ was applied during the full sintering cycle, while for "-2" samples the same uniaxial pressure starting to be applied (in a $1 \mathrm{~min}$ ramp) once the samples reached $1300^{\circ} \mathrm{C}$. Pressure application through the whole sintering cycle promotes grain size inhomogeneities which are remarkably reduced in a two-step pressure profile. Solute drag and improved grain boundary sliding by Mg-doping further reduced the grain size inhomogeneities [51]. (reprinted with permission from Elsevier). 
The intrinsic difficulties of SPS indicated by FEM modeling have allowed us to provide explanations for the recurrently observed inhomogeneities in the sample microstructure after sintering. To overcome these intrinsic difficulties (depending on the sample dimensions), a sintering cycle engineering approach proves fruitful as a means to overcome these inherent difficulties. Delaying the onset of the third sintering stage, where most grain growth occurs, as late as possible during the sintering cycle proves efficient without degrading the final density of the ceramics. The effect of two-step pressure cycles can be further enhanced through selective doping and/or two-step sintering cycles as successfully applied in conventional sintering techniques [52,53].

\section{Apparent Activation Energies and Predominant Mechanisms for Densification in SPS}

While the debate about the origins of the fast mass transport observed during SPS was vibrant, a first step towards the understanding of the underlying mechanisms was to evaluate the apparent activation energies for densification. Comparing the observed activation energies via the stress exponents to those observed in conventional sintering seemed like a promising approach to contribute to the discussion to the exclusion or identification of certain predominant factors.

In the quest towards careful colloidal processing free manufacturing of transparent alumina [3], alumina was once more chosen as a model material to investigate the effect of dopants on the sintering mechanism [54]. Hereby the combinatorial approach using the master sintering curve (MSC) as well as the constant heating rate method for the determination of the apparent activation energies proved particularly insightful. Whilst the constant heating rate method finds widespread use and acceptance in the community, it does not allow (in general) us to gain any knowledge about the predominant mechanism active during the final sintering stage (due to maximum temperature restrictions). From the FEM modeling work of the previous section, however, evidence was shown that the very final sintering stage is determinant in SPS and merits our full attention.

For naturally sintered Mg-doped alumina, it could be shown that the measured apparent activation energies are roughly independent of the selected measurement method (around 590-620 kJ/mol) and remain essentially constant throughout the sintering process (Figure 5) [54]. In case of SPS sintering, the apparent activation energy determined via the constant heating rate method indicated a substantially lower apparent activation energy for densification around $300 \mathrm{~kJ} / \mathrm{mol}$, indicative of a predominant mechanism change. The accessible data, however, was limited to densities below $85 \%$ relative density, thus excluding by default any information regarding the final sintering stage, expected to occur after pore closure at a relative density around $90-92 \%$.

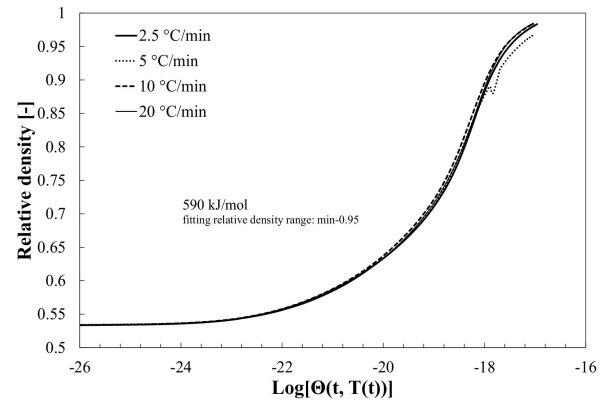

(a)

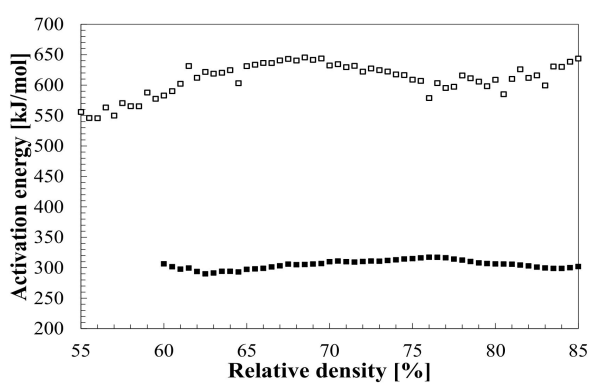

(b)

Figure 5. (a) Master sintering curve with corresponding apparent activation energy for natural sintering (i.e., in air, no pressure applied) of Mg-doped alumina. For all sintering curves, the data properly collapses into a single curve (except one artefact) indicating that a single predominant mechanism is active throughout the sintering cycle without any abnormal grain growth being expected to occur. (b) Apparent activation energies as a function of the density for natural (empty squares) and SPS (filled squares) sintering determined by the constant heating rate method. Extensive viscous flow in SPS sintering substantially reduces the apparent activation energy in the intermediate sintering stage [54]. (reprinted with permission of Materials Research Society). 
Indeed, stress exponent measurements gave a clear indication that a lower apparent activation energy for densification was to be expected at the intermediate sintering stage. During a dwell at $900{ }^{\circ} \mathrm{C}$, a stress exponent near 1 indicated viscous flow as a predominant sintering mechanism (Table 1 ). At $950{ }^{\circ} \mathrm{C}$, however, the stress exponent value changed and remained identical for higher dwell temperatures to values around 2. A sintering mechanism change was thus to be expected during the sintering cycle, evolving from viscous flow to grain boundary diffusion dominated mass flow during SPS of Mg-doped alumina.

Table 1. Stress exponent values for Mg-doped alumina sintered in SPS under $50 \mathrm{MPa}$ uniaxial pressure with various dwell temperatures. Dwell temperatures were reached within 2 min with consequently varying heating rates. A clear stress exponent change can be observed between $900{ }^{\circ} \mathrm{C}$ and $950{ }^{\circ} \mathrm{C}$ indicating a mechanism change from viscous flow towards grain boundary diffusion controlled densification [54]. (reprinted with permission of Materials Research Society).

\begin{tabular}{cc}
\hline Dwell Temperature $\left({ }^{\circ} \mathbf{C}\right)$ & Stress Exponent (-) \\
\hline 900 & 1.2 \\
950 & 2.3 \\
1000 & 2.1 \\
1050 & 2.1 \\
\hline
\end{tabular}

The change in predominant densification mechanism was revealed using the MSC for the SPS Mg-doped alumina as illustrated in Figure 6. For the first time, to our knowledge, a relative density-based interval methodology was used to allow for a stepwise construction of the MSC. In the error minimization procedure, the number of steps allowed a direct link to the number of experimentally observed predominant mechanism changes. Through this method, a reasonable fit between the apparent activation energies obtained via the MSC and constant heating rate method was achieved for Mg-doped alumina (Figure 6). The results furthermore gave reasonable evidence that no mass flow mechanism change is to be expected between the final sintering stage in SPS and natural sintering (i.e., in air, without any pressure applied). As a result of the very fast densification rates for Mg-doped alumina compared to Y-and La-doping, the evidence in the case of Mg-doping was less evident than in the case of the latter ones due to the experimental error on the dilatometry data during SPS and transition intervals between the subsequent dominant mechanisms.

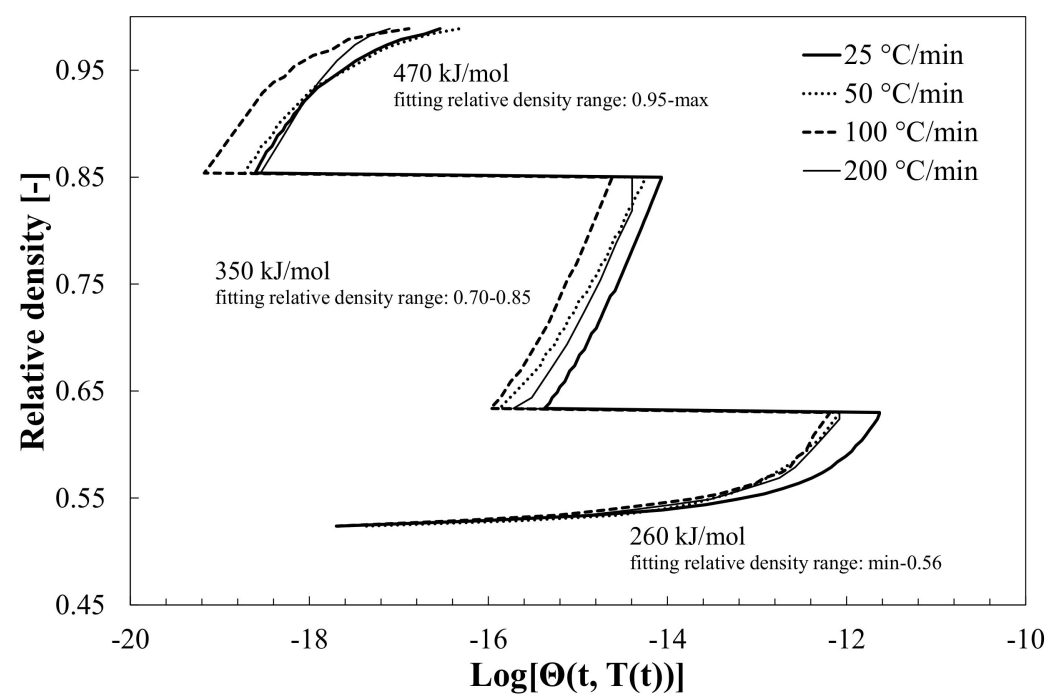

Figure 6. Master sintering curve with corresponding apparent activation energy for spark plasma sintering of Mg-doped alumina. Due to extensive viscous flow in the intermediate sintering stage, confirmed by a stress exponent analysis, the predominant mechanisms change during the sintering 
cycle such that the sintering curves do not collapse into a single domain master sintering curve (MSC) as it is the case for natural sintering in Figure 5a. Three distinct regimes exist in presence of a uniaxial sintering pressure: (I) particle rearrangement, (II) viscous flow, and (III) grain boundary diffusion each with their corresponding apparent activation energy as expected from the constant heating rate method in Figure 5b [54]. (reprinted with permission of Materials Research Society).

Especially in the case of Y-doped alumina, where no stress exponent change was observed and thus the intermediate and final sintering stage could be collapsed into a single MSC, the correspondence between the apparent activation energies was revealing (Figure 7). A total of $670 \mathrm{~kJ} / \mathrm{mol}$ in case of natural sintering as opposed to $690 \mathrm{~kJ} / \mathrm{mol}$ in case of SPS for Y-doped alumina. Similar to Mg-doping, a stress exponent change was again observed in the case of La-doping. The consequent 3-interval MSC collapsed with better accuracy because of the lower sintering rate and increased data points available during SPS dilatometry experiments.

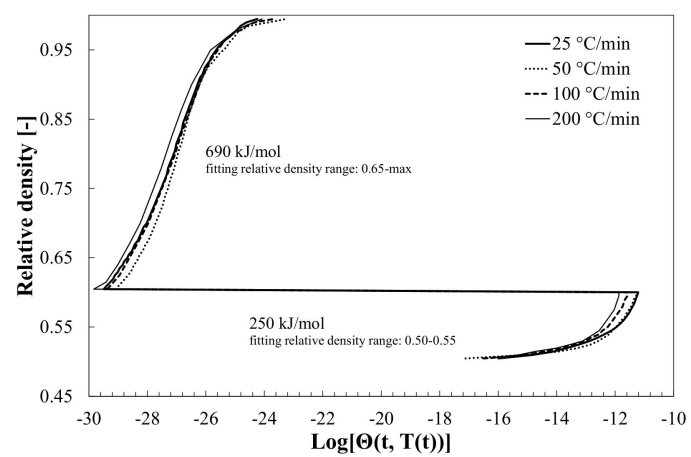

(a)

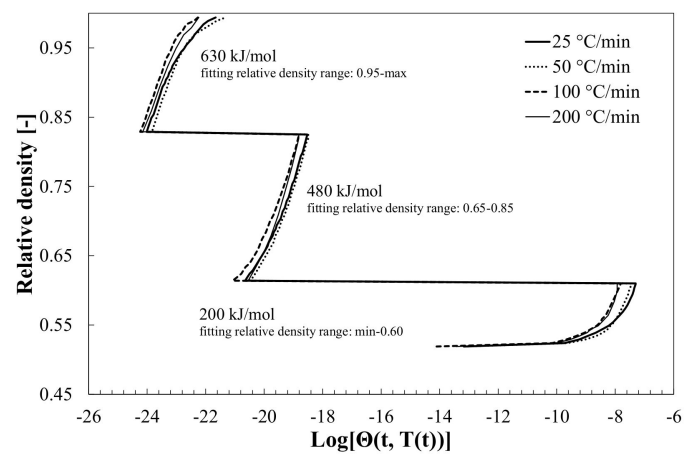

(b)

Figure 7. (a) Master sintering curve with corresponding apparent activation energy for spark plasma sintering of Y-doped alumina. Stress exponent measurements did not reveal any mechanism change, and after particle rearrangement at sintering onset, the sintering curves collapse into a single domain master curve with an apparent activation energy equivalent to the one measured in natural sintering $(670 \mathrm{~kJ} / \mathrm{mol})$. (b) Master sintering curve with corresponding apparent activation energy for spark plasma sintering of La-doped alumina. Due to extensive viscous flow in the intermediate sintering stage, confirmed by a stress exponent analysis and change, the predominant mechanisms change during the sintering cycle such that the sintering curves do not collapse into a single domain MSC. At the final sintering stage an apparent activation energy of $630 \mathrm{~kJ} / \mathrm{mol}$ is reasonably equivalent to the one measured in natural sintering varying between $700-780 \mathrm{~kJ} / \mathrm{mol}$ [54]. (reprinted with permission of Materials Research Society).

Despite the difficulties encountered in SPS dilatometry experiments, a combination of stress exponent and MSC measurement highlights and supports the assumptions laid out earlier by Olevsky et al. [14] and Bernard-Granger et al. [55]. Using doped-alumina as a study material, additional evidence was provided that SPS does not fundamentally change the sintering mechanisms $[54,56,57]$. The improved mass flow that must be a prerequisite under the given circumstances for the fast sintering rates observed in SPS was thus once more linked to an increased mass carrier density. The high heating rates and the microstructural inhomogeneities observed in SPS in addition to the higher mass carrier density though significantly differentiates SPS with the hot press sintering technique. With the evidence for spark discharges has been provided by Zhang et al. [12] as a possible origin for the increased mass carrier density, a reasonable understanding of the underlying mechanisms in SPS is now available.

The specificities of SPS may thus be a valuable asset in studying the dopant effects in the scope of complexion transitions, where the time-temperature profile plays a key role and the fast sintering and heating rates encountered in SPS suggest a promising approach $[43,46]$. 


\section{Effect of SPS Conditions on the Atomistic Defect Concentration and Thermal Stability}

As illustrated in both preceding sections, the SPS parameters and in particular the pressure cycle play an important role in the microstructural development and the atomic scale defect concentration in the sintered ceramic. While slow heating rates can certainly help prevent and/or anneal atomic scale defects, they suppress the very appeal of SPS: fast sintering cycles. It is thus necessary to analyze the circumstances that willingly or unwillingly generate atomic scale defects during SPS to promote or prevent their occurrence based on the actual objectives.

From the study on transparent $\mathrm{MgAl}_{2} \mathrm{O}_{4}$, it appeared already that single pressure cycles promote dislocation generation during sintering. In the case of magnesium spinel, dislocation cores successfully stabilized optically active oxygen vacancies with disastrous consequences on the optical properties [47]. Coming back to alumina, our material of choice in this topical paper, a similar behavior was observed when it is Mg-doped [32].

Studying the effect of the pressure cycle and the heating rate on the optical properties of Mg-doped alumina, no significant differences in the optical properties could be observed directly after SPS. Differences appeared after a post-thermal treatment conventionally used for thermal grooving of the Mg-doped alumina samples. While a 2-step pressure cycle renders the ceramic mostly insensitive to post-sintering thermal treatments, a single step pressure profile leads to a distinct yellowish coloration, with increasing intensity as the heating rate increases (Figure 8) [32].

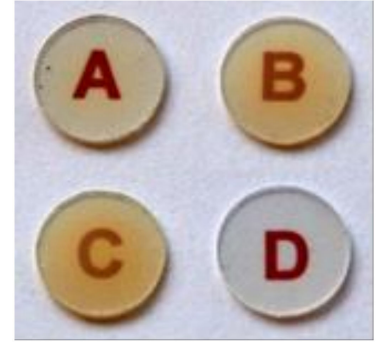

(a)

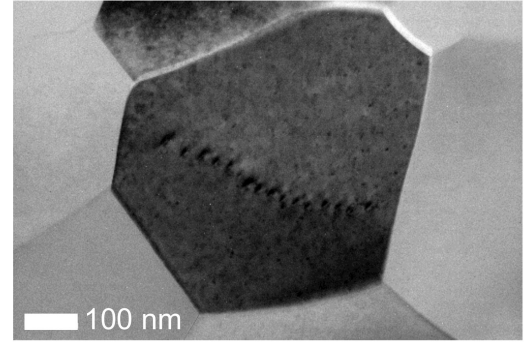

(b)

Figure 8. (a) Photos of SPS sintered Mg-doped alumina after post sintering thermal treatment at $1150{ }^{\circ} \mathrm{C}$ in air for $30 \mathrm{~min}$. The uniaxial sintering pressure of $100 \mathrm{MPa}$ was applied for $(\mathrm{A}-\mathrm{C})$ the whole sintering cycle and (D) at soak temperature only. The heating rates were for $(\mathbf{A}$ and $\mathbf{D}) 100{ }^{\circ} \mathrm{C} / \mathrm{min}$, (B) $233{ }^{\circ} \mathrm{C} / \mathrm{min}$ and (C) $350{ }^{\circ} \mathrm{C} / \mathrm{min}$. It can be observed that a single-step pressure cycle generates a yellowish coloration which increases with increasing heating rate. A two-step pressure profile avoids the coloration which can be explained in a similar way to that of the study on transparent $\mathrm{MgAl}_{2} \mathrm{O}_{4}$ [47].

(b) Dislocation walls observed in sample C in TEM, prior to thermal treatment.

Using FIB-Nanotomography to investigate microstructural changes occurring in the sample with most developed coloration (i.e., sample $C$ in Figure 8), it could be shown that the yellowish coloration accompanies an increase in porosity and pore size after post-sintering thermal treatment compared to the "as-sintered" state (Figure 9). The origins of this porosity increase are thought to be linked to severe dislocation generation during low-temperature viscous flow. Indeed, for C-type samples, dislocation walls could be readily observed in TEM prior to thermal treatment, as opposed to D-type samples where such observations could not be made (in agreement with the study on transparent $\mathrm{MgAl}_{2} \mathrm{O}_{4}$ ). After thermal treatment, no such dislocation walls could be observed, suggesting that the porosity increase is linked to migration and annealing of dislocations to form and/or increase porosities. Those results suggest that the pressure cycle as well as the heating ramp can be actively used to promote or inhibit atomistic scale defect generation during SPS. Such defects not only affect the properties of the sintered ceramics, but also their stability during post-sintering thermal exposure. Careful design of the sintering cycle is thus required in SPS, even if similar properties (e.g., optical) are observed in the as-sintered state. 


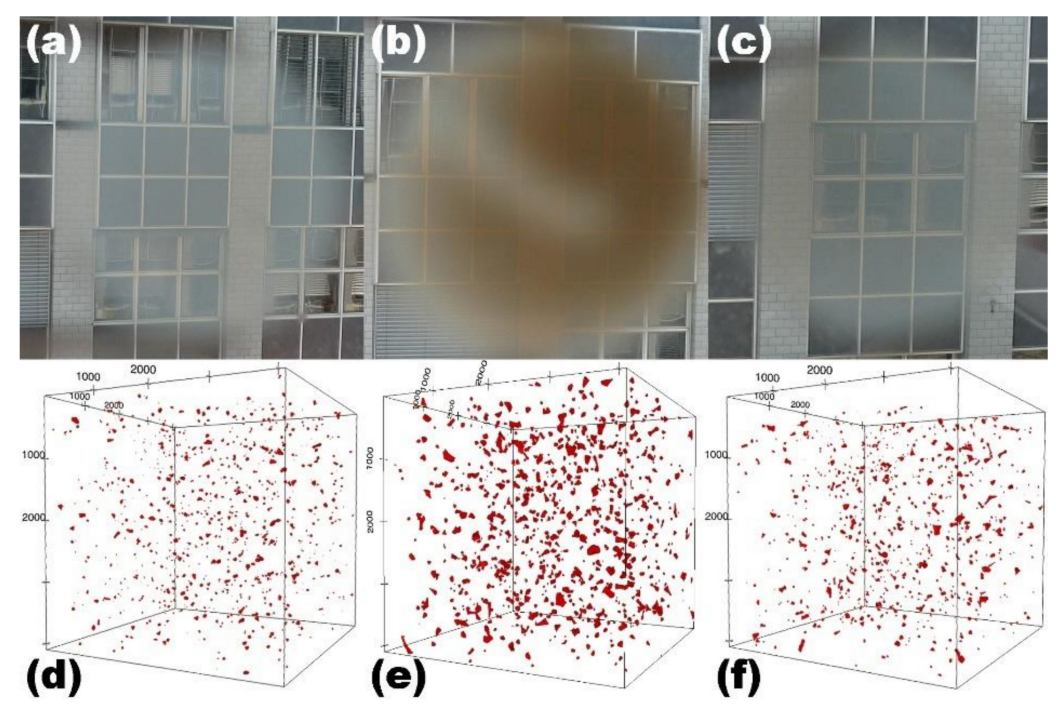

Figure 9. Sample images $(\mathbf{a}-\mathbf{c})$ and 3D-FIB tomography representations $(\mathbf{d}-\mathbf{f})$ of the porosity in the same samples at different treatment states: $(\mathbf{a}, \mathbf{d})$ as-sintered (sample C1); (b,e) after thermal treatment at $1150{ }^{\circ} \mathrm{C}$ (sample C2); and (c,f) after thermal treatment followed by post-HIP at 1500 bar (sample C3). All samples have been sintered at the same conditions as sample $C$ in Figure 8. The 3D-FIB pore reconstruction is of a $4.11 \cdot 4.11 \cdot 4.11 \mu \mathrm{m}^{3}$ volume for all three samples. Note that the uncolored area in the middle of sample $\mathrm{C} 2(\mathbf{b})$ resulted from dislocation release into a crack present in the sample before thermal treatment [32]. (reprinted with the permission from Wiley-VCH).

Despite the observation that the appearance and disappearance of the color went hand in hand with a porosity increase and decrease, respectively (Figure $9 b, c, e, f)$, the origins of the color resulting solely from a structural coloration effect remained hypothetical rather than experimentally substantiated. Additional evidence was thus required to corroborate the origins of the color.

After further work, a first confirmation came from the color calculation from the real in-line transmission (RIT) spectra of the C-sample series using the CIE D65 illuminant. After plotting the color on a CIE 1931 x, y color space chromaticity diagram (Figure 10), it was revealed that the full color information was included in the transmission spectra, precluding a light reflection effect [58]. Since the RIT spectra did not reveal any unusual features and followed the expected trend for polycrystalline alumina, the result further supports the hypothesis of a structural color effect due to pore scattering.

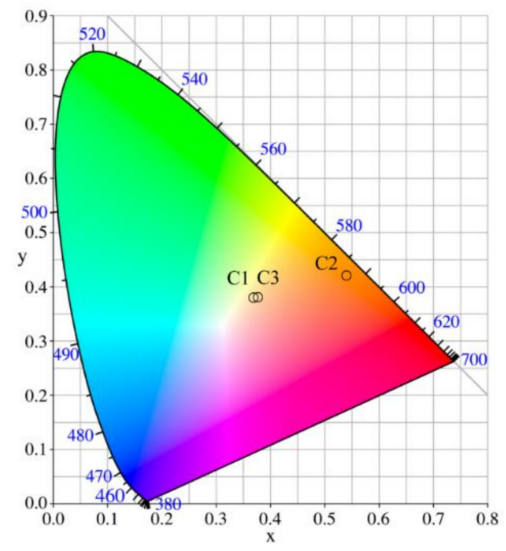

Figure 10. CIE 1931 x, y color space chromaticity diagram with the color calculation results circled for the $C$ series samples in their various states $C 1, C 2$, and C3 using the CIE D65 illuminant. Notice the more pronounced color for sample $\mathrm{C} 2$ compared to the sample $\mathrm{C}$ above. $\mathrm{C} 1$ and $\mathrm{C} 3$ give almost the same color [58]. 
No known color centers have been reported in literature for Mg-doped alumina that could explain the yellowish color [59]. Absorption spectra were nonetheless collected to rule out any peculiarities linked to SPS. The absorption spectra for the C-series samples are represented in Figure 11, after a first order correction of the raw absorption spectra due to light scattering by the pores increasing with decreasing wavelength [36]. Indeed, the larger scattering probability with decreasing wavelength increases the length light travels through the sample, artificially increasing the absorption coefficient for smaller wavelengths. A sketch of the experimental setup and the first order (single scattering) correction approach used can be found in detail in Appendix A.

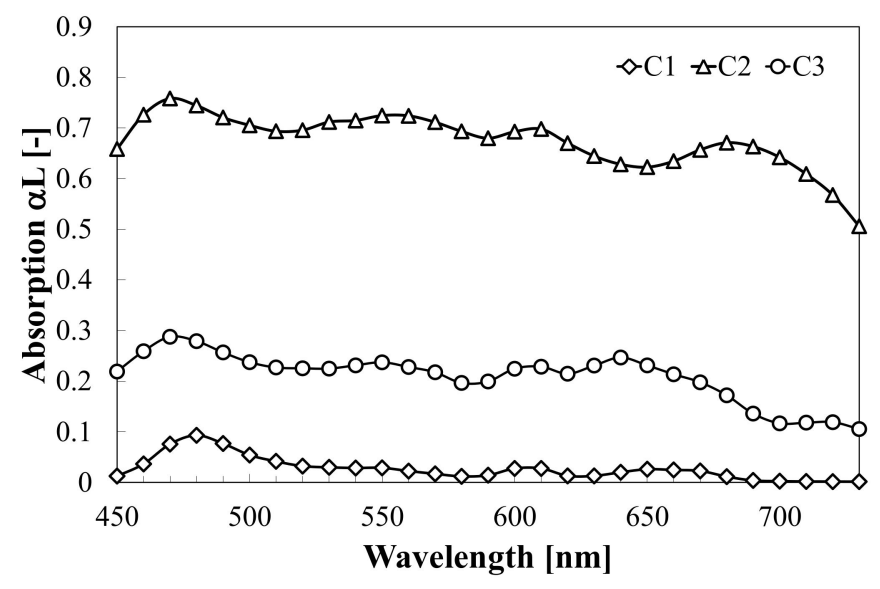

Figure 11. Absorption for $1 \mathrm{~mm}$ sample thickness approximately corrected for longer path lengths taking into account single scattering events from grains and pores within an angular range up to the total internal reflection [58].

The C-series absorption measurements revealed significant changes in the overall absorption coefficient, but no significant changes in the small absorption peaks (Figure 11). In particular, no characteristic absorption peak could be revealed that could explain the reversible appearance of color as shown for the C-series in Figure 9 above. The small peaks may be linked to Cr-impurities and the formation of oxygen vacancy clusters (Fx-type) as a result of Mg-doping. Although these results further support structural coloration as the sole origin of the yellow-brownish coloration, the foundation of the large broadband absorption in C2 and C3 samples could not be fully corroborated. It is believed that the broadband absorption changes (i.e., overall absorption coefficient changes) may be a result of metal colloid formation due to oxygen vacancy clustering, which in turn may lead to a broad background absorption [60]. Such metal colloids would also explain the partial recovery of the "as-sintered" optical properties, being resorbed incompletely after the final post-HIP treatment (sample C3). Using this absorption factor in addition to the factors linked to light scattering by the grains and pores, an excellent fitting between the theoretical calculation and experimental measurement of the RIT could be achieved, validating our approach [32].

In SPS, careful analysis of the sintering conditions is required to elucidate the origins of color and/or defects in the sintered ceramics. Together with the study on $\mathrm{MgAl}_{2} \mathrm{O}_{4}$ [47], our results show that carbon contamination or oxygen vacancies as a result of a reducing atmosphere in SPS is not a sufficient argument to explain discoloration issues and may be misleading. High dislocation creation rates, occurring during low temperature viscous flow, play a leading role in the coloration and thermal stability of the sintered ceramics. The high heating rates used to explore the full benefits of SPS accentuate the issue.

Whilst many studies focus on the temperature cycle, the pressure cycle in SPS is often neglected, leading to unsatisfactory results and misleading conclusions. Inhomogeneities between the sample edges and the central part are a strong indicator for sub-optimal design of the pressure profile. 
In addition to the temperature gradient within the sample, the inhomogeneous powder compaction under uniaxial pressure (and resulting viscous flow gradient) can also play a significant role.

\section{SPS for Dopant and Complexion Transition Studies}

In addition to the benefits of SPS in manufacturing of high-quality ceramic materials with tailored properties, SPS should prove a valuable tool in future research to further investigate complexions [43,46,61-65]. Based on complexion theory, complexion transitions are time and temperature dependent similar to phase transformations in bulk phases [43,46]. Being able to control the temperature and density almost independently through judicious temperature and pressure cycles in SPS proves thus particularly powerful. It allows synthesis of the samples required to substantiate the theory and generate particular microstructures of interest to learn about the kinetics involved in and induced by complexion transitions. Such complexion transitions can lead to variations in grain boundary plane and character distributions (GBPD and GBCD, respectively) of particular interest in controlled microstructure engineering through grain boundary engineering (Figure 12).

(a)

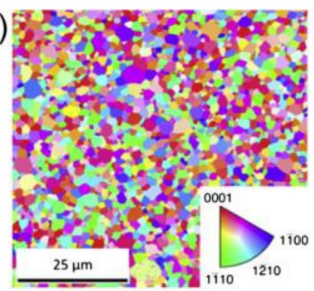

(d)

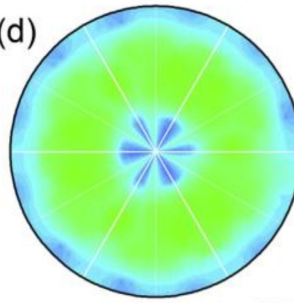

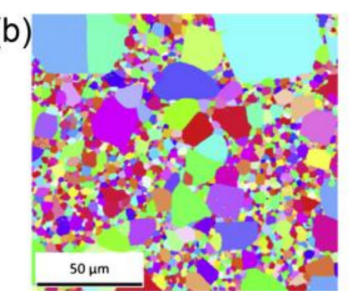

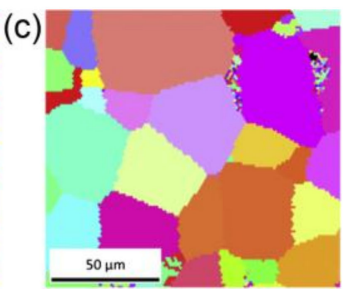

(e)

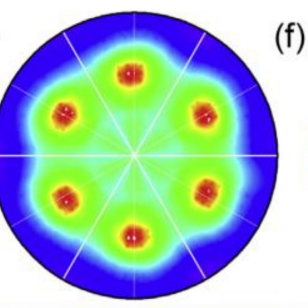

(f)

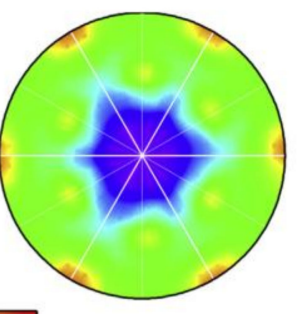

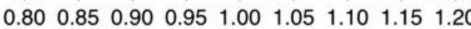

Multiples of Random

Figure 12. (a-c) Orientation maps illustrating the microstructures and (d-f) grain boundary plane distributions for 450 ppm Y-doped alumina. (a,d) $1450{ }^{\circ} \mathrm{C},(\mathbf{b}, \mathbf{e}) 1500{ }^{\circ} \mathrm{C},(\mathbf{c}, \mathbf{f}) 1600{ }^{\circ} \mathrm{C}$. The grain boundary plane distributions are plotted in stereographic projection with the [0001] direction normal to the page and the $[11 \overline{2} 0]$ reaction horizontal $[45,61]$. (reprinted with the permission from Wiley-VCH).

Since grain growth is essential in modifying the GBCD and GBPD as illustrated in Figure 12, but mostly occurs after reaching the final sintering stage, a two-step pressure profile is of particular interest. Given the final sintering stage can be reached at the selected sintering temperature (and sintering pressure), SPS provides the unique opportunity to evaluate the microstructure evolution at a given temperature, reasonably neglecting the thermal history of the sample and starting from a rather randomly distributed GBPD/GBCD.

Benefitting from the extensive knowledge acquired in the ceramic community on SPS, the conditions are ready to integrate SPS as a tool for more fundamental scientific studies on powder sintering and microstructure engineering.

\section{Conclusions}

Through a succinct summary of a decade of research by the authors on spark plasma sintering (SPS), recurring observations on SPS ceramics and their underlying mechanisms have been laid out using the example of alumina. Progress made by the community on the understanding and control of 
SPS as a sintering technique allows nowadays focusing in SPS on an industrial and scientific scale, on a knowledge-based product and material development, respectively.

To use the very key benefits of SPS - short sintering cycles and fast densification rates-both the sintering and pressure profiles have to be carefully chosen and optimized to avoid the undesired side effects of microstructural defects and thermal instabilities. In particular, pressure-induced atomic-scale defects may play a significant role in many physical properties of the ceramic materials and their stability upon post-sintering thermal exposure. When these are taken into account in the material production process, SPS becomes a viable and important tool for producing controlled microstructures leading to materials with improved properties and extended areas of application.

Author Contributions: Investigation, M.S. and Z.Z.; writing-original draft preparation, M.S.; writing一review and editing, P.B. and Z.Z.; supervision, P.B. and Z.Z.; funding acquisition, P.B. and Z.Z. All authors have read and agreed to the published version of the manuscript.

Funding: This research was funded by Swiss National Science Foundation, grant number 00021-122288/1 (M.S. and P.B.) and through EU Sixth Framework Programme IP-NANOKER, grant number NMP3-CT-2005-515784 (Z.Z. and P.B.).

Acknowledgments: Knut and Alice Wallenberg Foundation for the EM support (at Stockholm university), Marco Cantoni from EPFL for the FIB Nanotomography, Cheuk-Wai Tai for TEM support, Sophie Rallo and Lucile Lallemant contributing with their Master projects to the research progress, Prof. Paul Carry from SIMAP in Grenoble for the conventional dilatometry experiments, Stefan Geissbühler and Shanna Stuer for the support in absorption spectra measurements.

Conflicts of Interest: The authors declare no conflict of interest. The funders had no role in the design of the study; in the collection, analyses, or interpretation of data; in the writing of the manuscript, or in the decision to publish the results.

\section{Appendix A}

Absorption measurements are generally straightforward when light takes a direct path through the medium under investigation (Figure A1). In the presence of scattering events while traversing the sample, however, the travel path may become significantly longer than the thickness itself, adding a non-trivial degree of complication to the extraction of an absolute absorption coefficient due to the difficulty of knowing this exact path length. Simply using the sample thickness as the travel length indeed leads to a severe overestimation of the absorption coefficient. Furthermore, given that the average path length depends on the number of scattering events which extend the travel, the overestimation of the absorption will be more severe for samples with lower RIT.

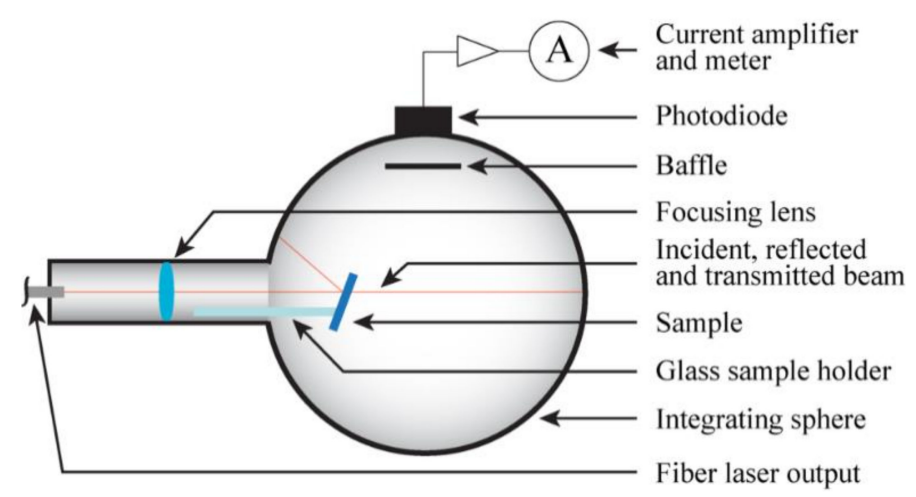

Figure A1. Schematic representation of the absorption measurement setup. The light source was a tunable filtered supercontinuum laser and the sample was inserted into the integrating sphere at an angle to keep the specular reflection inside the sphere.

Without an exact knowledge of the light travel distance through each sample, in order to extract a first estimate, a series of calculations was performed based on standard reflection and refraction laws. Each sample was mounted in the integrating sphere such that the angle of incidence of the light from 
the fiber was approximately $40.5^{\circ}$ from the surface normal. This angle was introduced intentionally so as to capture the specular reflection of the incident beam within the integrating sphere, rather than letting this reflection re-exit the input port. Snell's law may be used to calculate the angle at which the primary beam refracts into the material:

$$
n_{i} \sin \theta_{i}=n_{r} \sin \theta_{r}
$$

where the first refractive index is that of air $n_{i}=n_{\text {air }}=1$, the angle of incidence $\theta_{i}=40.5^{\circ}$, the refracted material index $n_{r}$ is taken as the average for alumina, $n_{r}=\frac{1}{2}\left(n_{e}+n_{0}\right)$, and the angle of refraction in the alumina is $\theta_{r}$. Calculating this angle yields $\theta_{r}=21.5^{\circ}$, again as measured from the sample normal. Whereas in the usual surface-normal RIT measurements the relevant light path is simply the sample thickness, here the nonzero angles of incidence and refraction imply that the distance $L$ that the primary beam travels is related to the thickness $d$ by $d=L \cos \theta_{r}$.

The distance that light travels before a scattering event may be estimated from the inverse of the RIT loss coefficient $\gamma_{\text {tot }}$. As this total measured loss coefficient also implicitly includes the absorption term, determining the distance between scattering events in this manner already represents an approximation. Nonetheless, one can consider that the amount of light entering the sample is reduced from the incident power by the first surface reflection $R_{1}$. The reflectance itself, however, is in general a function of the angle of incidence and the light polarization. The transverse-electric and transverse-magnetic reflection polarization components, denoted as s-polarized and p-polarized, are written as:

$$
\begin{aligned}
& R_{s}=\left(\frac{n_{1} \cos \theta_{1}-n_{2} \cos \theta_{2}}{n_{1} \cos \theta_{1}+n_{2} \cos \theta_{2}}\right)^{2}=\left(\frac{n_{1} \cos \theta_{1}-n_{2} \sqrt{1-\left(\frac{n_{1}}{n_{2}} \sin \theta_{1}\right)^{2}}}{n_{1} \cos \theta_{1}+n_{2} \sqrt{1-\left(\frac{n_{1}}{n_{2}} \sin \theta_{1}\right)^{2}}}\right)^{2} \\
& R_{p}=\left(\frac{n_{1} \cos \theta_{2}-n_{2} \cos \theta_{1}}{n_{1} \cos \theta_{2}+n_{2} \cos \theta_{1}}\right)^{2}=\left(\frac{n_{1} \sqrt{1-\left(\frac{n_{1}}{n_{2}} \sin \theta_{1}\right)^{2}}-n_{2} \cos \theta_{1}}{n_{1} \sqrt{1-\left(\frac{n_{1}}{n_{2}} \sin \theta_{1}\right)^{2}}+n_{2} \cos \theta_{1}}\right)^{2}
\end{aligned}
$$

From these formulae, it is easily seen that at normal incidence, where $\theta_{1}=\theta_{2}=90^{\circ}$, the cosine terms equal unity and the reflection coefficients simplify to the familiar difference over the sum of indexes, $R=R_{S}=R_{p}=\left(\frac{n_{1}-n_{2}}{n_{1}+n_{2}}\right)^{2}$. Using the refractive indexes of air and alumina at the angle of incidence of $40.5^{\circ}$, the above expressions yield $R_{s}=0.135$ and $R_{p}=0.033$. The value used for the surface reflection in this treatment is considered as the average of these two components, or $R_{1}=0.084$. The fraction of the total incident power entering the sample is thus $1-R_{1}$, some further fraction of which-as given by the RIT fraction-continues in the same direction as given by $\theta_{r}$ for a distance $L$. The rest, by definition, undergoes a scattering event which changes its direction, a distance given by the inverse scattering coefficient $\gamma^{-1}$.

After light is scattered from its primary $\theta_{r}=21.5^{\circ}$ direction through the sample, here it is considered equally likely that the photons will depart in any angular direction afterwards. In a further approximation, only forward scattering will be included in this treatment. This results in an important simplification regarding the range of scattered angles to be calculated. As a result that each angle represents a different path length traveled between the scattering event and the second (exit) surface of the sample, these path lengths must be integrated over the range of angles considered. For forward scattering, the upper angular limit is defined by the critical angle $\theta_{c}$ for total internal reflectance:

$$
\theta_{c}=\sin ^{-1}\left(\frac{n_{2}}{n_{1}}\right)
$$


where in this case $n_{2}=n_{\text {air }}=1$ since the light would be passing from alumina back into air. Using the average of the extraordinary and ordinary indexes for alumina, $n_{1}=\frac{1}{2}\left(n_{e}+n_{0}\right)$, the total internal reflection angle becomes $34.6^{\circ}$. All of the light incident upon the second surface is then subject to an angle-dependent degree of reflection. These different contributions are summarized schematically in Figure A2, with the incident amount from the source denoted by $I_{0}$.

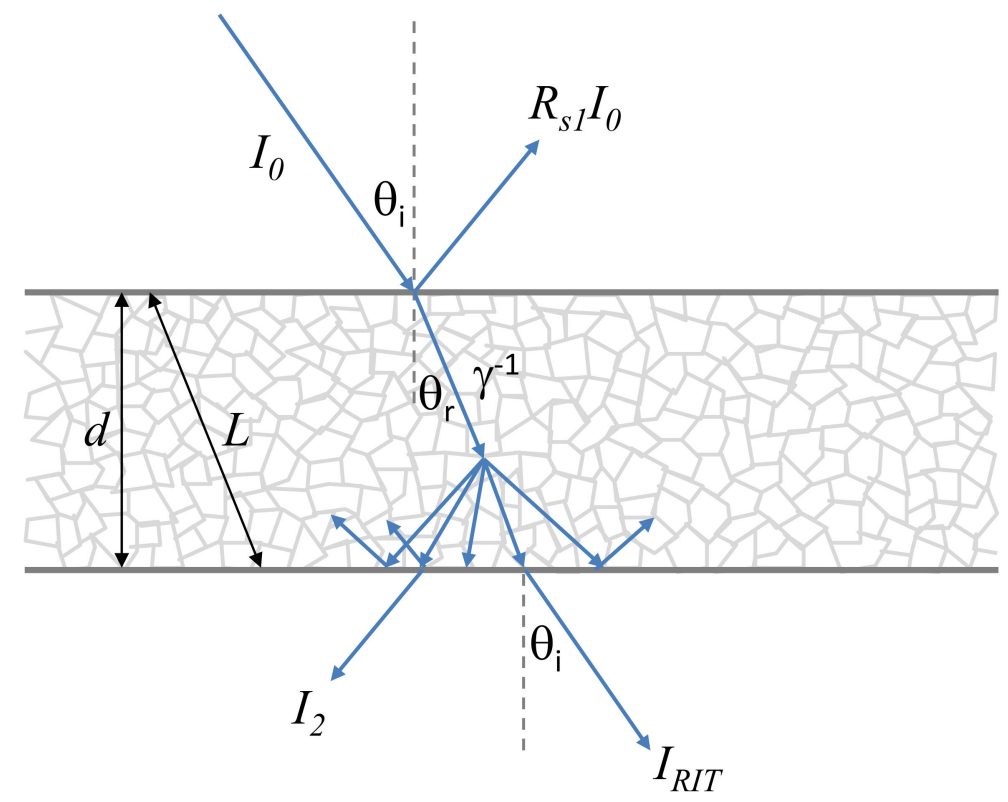

Figure A2. Schematic illustration of the different scattering contributions to the total path length.

The light entering the sample, $\left(1-R_{s 1}\right) I_{0}$, in principle, travels on average a distance given by the absorption-corrected inverse scattering coefficient, $\gamma^{-1}$, before changing direction. This value is related to the one measured from the RIT experiments by $\gamma=\gamma_{\text {tot }}-\alpha$. The distance from the scattering event to the second surface normal, determined solely from geometric considerations, is related to the "RIT" travel length $L$ and scattering length $\gamma$ by $\left(L-\gamma^{-1}\right) \cos \theta_{r}$. More generally, for an arbitrary scattering angle $\theta$, the distance traveled by a photon between the scattering event, and the second surface is given by $l=\left(L-\gamma^{-1}\right) \frac{\cos \theta_{r}}{\cos \theta}$.

The amount of light exiting the alumina-air interface may be considered as two separate terms: one for the primary beam that is refracted back to the original direction $\theta_{i}$ as measured in an RIT experiment, denoted here as $I_{R I T}$; and a second consisting of the integrated power of all the light scattered, $I_{\text {scatt }}$. As a result that the interface reflection is angle-dependent, the transmitted $I_{\text {RIT }}$ term may be specified as:

$$
I_{R I T}=\left(1-R_{s 1}\left(\theta_{i}\right)\right) I_{0} e^{-\alpha L} e^{-\gamma L}\left(1-R_{s 2}\left(\theta_{r}\right)\right)
$$

where $\gamma$ represents the grain-scattering and pore-scattering contributions. The second term, $I_{2}$, must be integrated over the angular range up to the total internal reflectance angle for forward scattering:

$$
\begin{gathered}
I_{2}=\left(1-R_{s 1}\left(\theta_{i}\right)\right) I_{0} \int_{-\theta_{T I R}}^{\theta_{T I R}} e^{-\alpha l}\left(1-R_{s 2}(\theta)\right) d \theta / \int_{-\theta_{T I R}}^{\theta_{T I R}} d \theta \\
=\left(1-R_{S 1}\left(\theta_{i}\right)\right) I_{0} \frac{1}{2 \theta_{T I R}} \int_{-\theta_{T I R}}^{\theta_{T I R}} e^{-\alpha\left(L-\gamma^{-1}\right) \frac{\cos \theta_{r}}{\cos \theta}}\left(1-R_{S 2}(\theta)\right) d \theta
\end{gathered}
$$

The intensity of light exiting the second sample surface can thus be considered as the sum of these terms weighted by the RIT fraction, i.e., $I=f_{R I T} I_{R I T}+\left(1-f_{R I T}\right) I_{2}$. It must be noted that this 
expression neglects all the light that is either back-scattered or forward-scattered outside of the range given by the total internal reflectance angle $\pm \theta_{T I R}$, as well as light reflected at the second interface back into the alumina sample. These factors represent corrections to the $I_{2}$ term beyond the first-order path length calculation described above, and can be accounted for qualitatively by adding an ad-hoc term inversely proportional to the dimensionless $\alpha l^{\prime}$ in the above sum.

Including the reflection from the first air-alumina interface, the total intensity of light detected in the integrating sphere becomes:

$$
I_{\text {det }}=I_{0} R_{s 1}\left(\theta_{i}\right)+f_{R I T} I_{R I T}+\left(1-f_{R I T}\right) I_{2}+c|\alpha|^{-1}
$$

or

$$
\begin{gathered}
\frac{I_{d e t}}{I_{0}}=R_{s 1}\left(\theta_{i}\right)+f_{R I T}\left(1-R_{s 1}\left(\theta_{i}\right)\right) e^{-\alpha L} e^{-\gamma L}\left(1-R_{S 2}\left(\theta_{r}\right)\right)+ \\
\left(1-R_{s 1}\left(\theta_{i}\right)\right)\left(1-f_{R I T}\right) \frac{1}{2 \theta_{T I R}} \int_{-\theta_{\text {TIR }}}^{\theta_{\text {TIR }}} e^{-\alpha\left(L-\gamma^{-1}\right) \frac{\cos \theta_{r}}{\cos \theta}\left(1-R_{s 2}(\theta)\right) d \theta+c|\alpha|^{-1}}
\end{gathered}
$$

Practically, because this expression is transcendental for the absorption implicitly through the exponential of the RIT term as well as explicitly in the $I_{2}$ and multiple-reflection-scattering terms, it must be solved numerically. Compared to the absorption calculated from the uncorrected path length, i.e., calculating $\alpha$ based only on the as-is measured intensity, the value of $\alpha d$ is reduced by approximately 0.1 . For the least transparent sample considered, the reduction of the optical depth from about $\alpha d=0.8$ to $\alpha d=0.7$ represents a change of about $12 \%$, while for the most transparent sample having an unadjusted depth of about $\alpha d=0.1$, this represents a correction of nearly $100 \%$ of the uncorrected value.

\section{References}

1. Zhao, Z.; Buscaglia, V.; Bowen, P.; Nygren, M. Spark plasma sintering of nano-crystalline ceramics. Key Eng. Mater. 2004, 264, 2297-2300. [CrossRef]

2. Trunec, M.; Maca, K.; Chmelik, R. Polycrystalline alumina ceramics doped with nanoparticles for increased transparency. J. Eur. Ceram. Soc. 2015, 35, 1001-1009. [CrossRef]

3. Stuer, M.; Zhao, Z.; Aschauer, U.; Bowen, P. Transparent polycrystalline alumina using spark plasma sintering: Effect of Mg, Y and La doping. J. Eur. Ceram. Soc. 2010, 30, 1335-1343. [CrossRef]

4. Morita, K.; Kim, B.N.; Yoshida, H.; Hiraga, K.; Sakka, Y. Influence of Spark Plasma Sintering (SPS) Conditions on Transmission of $\mathrm{MgAl}_{2} \mathrm{O}_{4}$ Spinel. J. Am. Ceram. Soc. 2015, 98, 378-385. [CrossRef]

5. Grasso, S.; Yoshida, H.; Porwal, H.; Sakka, Y.; Reece, M. Highly transparent alpha-alumina obtained by low cost high pressure SPS. Ceram. Int. 2013, 39, 3243-3248. [CrossRef]

6. Borodianska, H.; Ludvinskaya, T.; Sakka, Y.; Uvarova, I.; Vasylkiv, O. Bulk Ti1-xAlxN nanocomposite via spark plasma sintering of nanostructured Ti1-xAlxN-AlN powders. Scr. Mater. 2009, 61, 1020-1023. [CrossRef]

7. Bernard-Granger, G.; Monchalin, N.; Guizard, C. Comparisons of grain size-density trajectory during spark plasma sintering and hot-pressing of zirconia. Mater. Lett. 2008, 62, 4555-4558. [CrossRef]

8. Aimable, A.; Doubi, H.G.; Stuer, M.; Zhao, Z.; Bowen, P. Synthesis and Sintering of ZnO Nanopowders. Technologies 2017, 5, 28. [CrossRef]

9. Perera, D.S.; Tokita, M.; Moricca, S. Comparative study of fabrication of $\mathrm{Si}_{3} \mathrm{~N}_{4} / \mathrm{SiC}$ composites by spark plasma sintering and hot isostatic pressing. J. Eur. Ceram. Soc. 1998, 18, 401-404. [CrossRef]

10. Tang, Y.; Xue, J.X.; Zhang, G.J;; Wang, X.G.; Xu, C.M. Microstructural differences and formation mechanisms of spark plasma sintered ceramics with or without boron nitride wrapping. Scr. Mater. 2014, 75, 98-101. [CrossRef]

11. Hulbert, D.M.; Anders, A.; Andersson, J.; Lavernia, E.J.; Mukherjee, A.K. A discussion on the absence of plasma in spark plasma sintering. Scr. Mater. 2009, 60, 835-838. [CrossRef] 
12. Zhang, Z.H.; Liu, Z.F.; Lu, J.F.; Shen, X.B.; Wang, F.C.; Wang, Y.D. The sintering mechanism in spark plasma sintering-Proof of the occurrence of spark discharge. Scr. Mater. 2014, 81, 56-59. [CrossRef]

13. Hu, Z.Y.; Zhang, Z.H.; Cheng, X.W.; Wang, F.C.; Zhang, Y.F.; Li, S.L. A review of multi-physical fields induced phenomena and effects in spark plasma sintering: Fundamentals and applications. Mater. Des. 2020, 191, 108662. [CrossRef]

14. Olevsky, E.A.; Froyen, L. Impact of Thermal Diffusion on Densification During SPS. J. Am. Ceram. Soc. 2009, 92, S122-S132. [CrossRef]

15. Bernard-Granger, G.; Addad, A.; Fantozzi, G.; Bonnefont, G.; Guizard, C.; Vernat, D. Spark plasma sintering of a commercially available granulated zirconia powder: Comparison with hot-pressing. Acta Mater. 2010, 58, 3390-3399. [CrossRef]

16. Demirskyi, D.; Borodianska, H.; Agrawal, D.; Ragulya, A.; Sakka, Y.; Vasylkiv, O. Peculiarities of the neck growth process during initial stage of spark-plasma, microwave and conventional sintering of WC spheres. J. Alloys Compd. 2012, 523, 1-10. [CrossRef]

17. Bonifacio, C.S.; Holland, T.B.; van Benthem, K. Evidence of surface cleaning during electric field assisted sintering. Scr. Mater. 2013, 69, 769-772. [CrossRef]

18. Orru, R.; Licheri, R.; Locci, A.M.; Cincotti, A.; Cao, G.C. Consolidation/synthesis of materials by electric current activated/assisted sintering. Mater. Sci. Eng. R 2009, 63, 127-287. [CrossRef]

19. Wang, X.; Casolco, S.R.; Xu, G.; Garay, J.E. Finite element modeling of electric current-activated sintering: The effect of coupled electrical potential, temperature and stress. Acta Mater. 2007, 55, 3611-3622. [CrossRef]

20. Zavaliangos, A.; Zhang, J.; Krammer, M.; Groza, J.R. Temperature evolution during field activated sintering. Mater. Sci. Eng. A Struct. 2004, 379, 218-228. [CrossRef]

21. Anselmi-Tamburini, U.; Gennari, S.; Garay, J.E.; Munir, Z.A. Fundamental investigations on the spark plasma sintering/synthesis process-II. Modeling of current and temperature distributions. Mater. Sci. Eng. A Struct. 2005, 394, 139-148. [CrossRef]

22. Bernard-Granger, G.; Benameur, N.; Guizard, C.; Nygren, M. Influence of graphite contamination on the optical properties of transparent spinel obtained by spark plasma sintering. Scr. Mater. 2009, 60, 164-167. [CrossRef]

23. Kim, B.N.; Prajatelistia, E.; Han, Y.H.; Son, H.W.; Sakka, Y.; Kim, S. Transparent hydroxyapatite ceramics consolidated by spark plasma sintering. Scr. Mater. 2013, 69, 366-369. [CrossRef]

24. Lallemant, L.; Fantozzi, G.; Garnier, V.; Bonnefont, G. Transparent polycrystalline alumina obtained by SPS: Green bodies processing effect. J. Eur. Ceram. Soc. 2012, 32, 2909-2915. [CrossRef]

25. Morita, K.; Kim, B.N.; Hiraga, K.; Yoshida, H. Fabrication of high-strength transparent $\mathrm{MgAl}_{2} \mathrm{O}_{4}$ spinel polycrystals by optimizing spark-plasma-sintering conditions. J. Mater. Res. 2009, 24, 2863-2872. [CrossRef]

26. Morita, K.; Kim, B.N.; Yoshida, H.; Sakka, Y.; Hiraga, K. Fabrication of transparent $\mathrm{MgAl}_{2} \mathrm{O}_{4}$ spinel by optimizing loading schedule during Spark-Plasma-Sintering. Ceram. Trans. 2014, 243, 173-180. [CrossRef]

27. Roussel, N.; Lallemant, L.; Chane-Ching, J.Y.; Guillemet-Fristch, S.; Durand, B.; Garnier, V.; Bonnefont, G.; Fantozzi, G.; Bonneau, L.; Trombert, S.; et al. Highly Dense, Transparent-Al2O3 Ceramics From Ultrafine Nanoparticles Via a Standard SPS Sintering. J. Am. Ceram. Soc. 2013, 96, 1039-1042. [CrossRef]

28. Sokol, M.; Ratzker, B.; Kalabukhov, S.; Dariel, M.P.; Galun, E.; Frage, N. Transparent Polycrystalline Magnesium Aluminate Spinel Fabricated by Spark Plasma Sintering. Adv. Mater. 2018, 30. [CrossRef]

29. Trunec, M.; Klimke, J.; Shen, Z.J. Transparent alumina ceramics densified by a combinational approach of spark plasma sintering and hot isostatic pressing. J. Eur. Ceram. Soc. 2016, 36, 4333-4337. [CrossRef]

30. Wang, C.; Zhao, Z. Transparent polycrystalline ruby ceramic by spark plasma sintering. Mater. Res. Bull. 2010, 45, 1127-1131. [CrossRef]

31. Stuer, M.; Bowen, P. Colloidal Processing and Yield Stress Modeling Towards Dry Pressed Green Bodies for Transparent Polycrystalline Alumina. Adv. Eng. Mater. 2014, 16, 774-784. [CrossRef]

32. Stuer, M.; Bowen, P.; Cantoni, M.; Pecharroman, C.; Zhao, Z. Nanopore Characterization and Optical Modeling of Transparent Polycrystalline Alumina. Adv. Funct. Mater. 2012, 22, 2303-2309. [CrossRef]

33. Stuer, M.; Zhao, Z.; Bowen, P. Freeze granulation: Powder processing for transparent alumina applications. J. Eur. Ceram. Soc. 2012, 32, 2899-2908. [CrossRef]

34. Apetz, R.; van Bruggen, M.P.B. Transparent alumina: A light-scattering model. J. Am. Ceram. Soc. 2003, 86, 480-486. [CrossRef] 
35. Peelen, J.G.J.; Metselaar, R. Light-Scattering by Pores in Polycrystalline Materials-Transmission Properties of Alumina. J. Appl. Phys. 1974, 45, 216-220. [CrossRef]

36. Pecharroman, C.; Mata-Osoro, G.; Diaz, L.A.; Torrecillas, R.; Moya, J.S. On the transparency of nanostructured alumina: Rayleigh-Gans model for anisotropic spheres. Opt. Express 2009, 17, 6899-6912. [CrossRef]

37. Chen, I.W.; Wang, X.H. Sintering dense nanocrystalline ceramics without final-stage grain growth. Nature 2000, 404, 168-171. [CrossRef]

38. Li, B.R.; Liu, D.Y.; Liu, J.J.; Hou, S.X.; Yang, Z.W. Two-step sintering assisted consolidation of bulk titania nano-ceramics by spark plasma sintering. Ceram. Int. 2012, 38, 3693-3699. [CrossRef]

39. Loh, N.J.; Simao, L.; Faller, C.A.; De Noni, A.; Montedo, O.R.K. A review of two-step sintering for ceramics. Ceram. Int. 2016, 42, 12556-12572. [CrossRef]

40. Bowen, P.; Carry, C.; Luxembourg, D.; Hofmann, H. Colloidal processing and sintering of nanosized transition aluminas. Powder Technol. 2005, 157, 100-107. [CrossRef]

41. Bojarski, S.A.; Harmer, M.P.; Rohrer, G.S. Influence of grain boundary energy on the nucleation of complexion transitions. Scr. Mater. 2014, 88, 1-4. [CrossRef]

42. Bojarski, S.A.; Knighting, J.; Ma, S.L.; Lenthe, W.; Harmer, M.P.; Rohrer, G.S. The Relationship Between Grain Boundary Energy, Grain Boundary Complexion Transitions, and Grain Size in Ca-doped Yttria. Mater. Sci. Forum 2013, 753, 87-92. [CrossRef]

43. Cantwell, P.R.; Frolov, T.; Rupert, T.J.; Krause, A.R.; Marvel, C.J.; Rohrer, G.S.; Rickman, J.M.; Harmer, M.P. Grain Boundary Complexion Transitions. Annu. Rev. Mater. Res. 2020, 50, 465-492. [CrossRef]

44. Harmer, M.P.; Rohrer, G.S. Grain boundary complexions-Current status and future directions. Curr. Opin. Solid State Mater. Sci. 2016, 20, iv-v. [CrossRef]

45. Rohrer, G.S. The role of grain boundary energy in grain boundary complexion transitions. Curr. Opin. Solid State Mater. Sci. 2016, 20, 231-239. [CrossRef]

46. Schumacher, O.; Marvel, C.J.; Kelly, M.N.; Cantwell, P.R.; Vinci, R.P.; Rickman, J.M.; Rohrer, G.S.; Harmer, M.P. Complexion time-temperature-transformation (TTT) diagrams: Opportunities and challenges. Curr. Opin. Solid State Mater. Sci. 2016, 20, 316-323. [CrossRef]

47. Wang, C.; Zhao, Z. Transparent MgAl2O4 ceramic produced by spark plasma sintering. Scr. Mater. 2009, 61, 193-196. [CrossRef]

48. Wang, C.; Cheng, L.F.; Zhao, Z. FEM analysis of the temperature and stress distribution in spark plasma sintering: Modelling and experimental validation. Comp. Mater. Sci. 2010, 49, 351-362. [CrossRef]

49. Olevsky, E.A.; Garcia-Cardona, C.; Bradbury, W.L.; Haines, C.D.; Martin, D.G.; Kapoor, D. Fundamental Aspects of Spark Plasma Sintering: II. Finite Element Analysis of Scalability. J. Am. Ceram. Soc. 2012, 95, 2414-2422. [CrossRef]

50. Giuntini, D.; Olevsky, E.A.; Garcia-Cardona, C.; Maximenko, A.L.; Yurlova, M.S.; Haines, C.D.; Martin, D.G.; Kapoor, D. Localized Overheating Phenomena and Optimization of Spark-Plasma Sintering Tooling Design. Materials 2013, 6, 2612-2632. [CrossRef]

51. Wang, C.; Wang, X.; Zhao, Z. Microstructure homogeneity control in spark plasma sintering of $\mathrm{Al}_{2} \mathrm{O}_{3}$ ceramics. J. Eur. Ceram. Soc. 2011, 31, 231-235. [CrossRef]

52. Wang, X.H.; Chen, P.L.; Chen, I.W. Two-step sintering of ceramics with constant grain-size, I. $\mathrm{Y}_{2} \mathrm{O}_{3}$. J. Am. Ceram. Soc. 2006, 89, 431-437. [CrossRef]

53. Wang, X.H.; Deng, X.Y.; Bai, H.L.; Zhou, H.; Qu, W.G.; Li, L.T.; Chen, I.W. Two-step sintering of ceramics with constant grain-size, II: $\mathrm{BaTiO}_{3}$ and Ni-Cu-Zn ferrite. J. Am. Ceram. Soc. 2006, 89, 438-443. [CrossRef]

54. Stuer, M.; Carry, C.P.; Bowen, P.; Zhao, Z. Comparison of apparent activation energies for densification of alumina powders by pulsed electric current sintering (spark plasma sintering) and conventional sintering-toward applications for transparent polycrystalline alumina. J. Mater. Res. 2017, 32, 3309-3318. [CrossRef]

55. Bernard-Granger, G.; Guizard, C. Spark plasma sintering of a commercially available granulated zirconia powder: I. Sintering path and hypotheses about the mechanism(s) controlling densification. Acta Mater. 2007, 55, 3493-3504. [CrossRef]

56. Boldin, M.S.; Popov, A.A.; Lantsev, E.A.; Nokhrin, A.V.; Chuvil'deev, V.N. Investigation of the kinetics of spark plasma sintering of alumina ceramics. Part 1. The initial stage of sintering. IOP Conf. Ser. Mater. Sci. Eng. 2019, 558, 012005. [CrossRef] 
57. Boldin, M.S.; Popov, A.A.; Lantsev, E.A.; Nokhrin, A.V.; Chuvil'deev, V.N. Investigation of the kinetics of spark plasma sintering of alumina. Part 2. Intermediate and final stages of sintering. IOP Conf. Ser. Mater. Sci. Eng. 2019, 558, 012006. [CrossRef]

58. Stuer, M. Transparent Polycrystalline Alumina: Processing, Sintering and Microstructural Analysis. Ph.D. Thesis, Ecole Polytechnique Fédérale de Lausanne (EPFL), Lausanne, Switzerland, 2012.

59. Brock, L.R.; Mishra, K.C.; Raukas, M.; Lapatovich, W.P.; Wei, G.C. Color Centers in Magnesium Doped Polycrystalline Alumina. MRS Proc. 2001, 667. [CrossRef]

60. Morono, A.; Hodgson, E.R. Enhanced oxygen vacancy aggregation and colloid production in $\mathrm{Al}_{2} \mathrm{O}_{3}$. J. Nucl. Mater. 1997, 250, 156-163. [CrossRef]

61. Bojarski, S.A.; Stuer, M.; Zhao, Z.; Bowen, P.; Rohrer, G.S. Influence of Y and La Additions on Grain Growth and the Grain-Boundary Character Distribution of Alumina. J. Am. Ceram. Soc. 2014, 97, 622-630. [CrossRef]

62. Tewari, A.; Galmarini, S.; Stuer, M.; Bowen, P. Atomistic modeling of the effect of codoping on the atomistic structure of interfaces in alpha-alumina. J. Eur. Ceram. Soc. 2012, 32, 2935-2948. [CrossRef]

63. Tewari, A.; Nabiei, F.; Parker, S.C.; Cantoni, M.; Stuer, M.; Bowen, P.; Hebert, C. Toward Knowledge-Based Grain-Boundary Engineering of Transparent Alumina Combining Advanced TEM and Atomistic Modeling. J. Am. Ceram. Soc. 2015, 98, 1959-1964. [CrossRef]

64. Cantwell, P.R.; Tang, M.; Dillon, S.J.; Luo, J.; Rohrer, G.S.; Harmer, M.P. Grain boundary complexions. Acta Mater. 2014, 62, 1-48. [CrossRef]

65. Krause, A.R.; Cantwell, P.R.; Marvel, C.J.; Compson, C.; Rickman, J.M.; Harmer, M.P. Review of grain boundary complexion engineering: Know your boundaries. J. Am. Ceram. Soc. 2019, 102, 778-800. [CrossRef]

Publisher's Note: MDPI stays neutral with regard to jurisdictional claims in published maps and institutional affiliations. 